\title{
Effects of nanoparticles on hydraulic cavitation
}

\author{
Min-rui Chen ${ }^{1}$, Jin-yuan Qian ${ }^{1,2, *}$, Zan $\mathrm{Wu}^{2}$, Chen Yang $^{1}$, Zhi-jiang $\mathrm{Jin}^{1}$, and Bengt Sunden ${ }^{2}$ \\ ${ }^{1}$ Institute of Process Equipment, College of Energy Engineering, Zhejiang University, Hangzhou, 310027, PR China \\ ${ }^{2}$ Department of Energy Sciences, Lund University, P. O. Box 118, SE-22100 Lund, Sweden
}

\begin{abstract}
When liquids flowing through a throttling element, such as a perforated plate, the velocity increases and the pressure decreases. If the pressure is below the saturated vapor pressure, the liquid will vaporize into small bubbles, which is called hydraulic cavitation. In fact, vaporization nucleus is another crucial condition for vaporizing. The nanoparticles contained in the nanofluids play a significant role in vaporization of liquids. In this paper, the effects of the nanoparticles on hydraulic cavitation are investigated. Firstly, a geometric model of a pipe channel equipped with a perforated plate is established. Then with different nanoparticle volume fractions and diameters, the nanofluids flowing through the channel is numerically simulated based on a validated numerical method. The operation conditions, such as the temperature and the pressure ratio of inlet to outlet, are the considered variables. As a significant parameter, cavitation numbers under different operation conditions are achieved to investigate the effects of nanoparticles on hydraulic cavitation. Meanwhile, the contours are extracted to research the distribution of bubbles for further investigation. This study is of interests for researchers working on hydraulic cavitation or nanofluids.
\end{abstract}

\section{Introduction}

Blocked by a throttling element, the fluid flow velocity increases and the pressure decreases. If the pressure is below the saturated vapor pressure of the liquid, the liquid vaporize to small bubbles, causing hydraulic cavitation. The cavitation may do damage to the hydraulic equipment, on the other hand, cavitation can be used in variety fields, such as sewage treatment, mass transfer and heat transfer promotion. Orifice plates and perforated plates are widely used to induce cavitation, and many scholars have contributed in this filed.

Adopting the tool combined with theoretical, numerical and experimental methods, Ebrahimi et al. [1] investigated a high-pressure cavitation flow induced by a thick orifice plate to obtain a critical ratio of downstream pressure to upstream pressure. Rudolf et al. [2] conducted experiments to explore dynamics of the cavitation flow downstream orifice plates. Wang et al. [3] investigated the cavitation flow and cavitation-induced erosion by mean of experiment. Araoye et al. [4] explore the flow through multi-stage restricting orifices by mean of numerical simulation. Zhang et al. [5] employed the particle image velocimetry to investigate the cavitation flow characteristics downstream different kinds of triangular multi-orifice plates. He et al. [6] investigated the hydrodynamic cavitation in single-hole orifice plate by means of visualized experiment and numerical simulation. Tao et al. [7] investigated the sound generation mechanisms of orifice plates. Qian et al. [8-9] analyzed the Mach number on multi-stage perforated plates inside a high pressure reducing valve, and put forward a method to reduce the aerodynamic noises. Carpenter et al. [10] conducted experiments in detail to explore the effects of geometrical parameters on the production of oil in water emulsion. Kabeel et al. [11] investigated the effects of the alumina nanofluid concentration on the characteristics of sharp-edge orifice flow, basing on a model of a single-hole orifice plate. Shaaban [12] optimized the orifice flowmeter for liquid hydrogen and obtained a novel orifice flowmeter. Liu et al. [13] applied perforated plate flowmeters to measure the flow rate of cryogenic fluids. Aided by numerical simulation, the characteristics of perforated plates were investigated. Zhang et al. [14] investigated how a diffuser orifice plate affects the flow characteristics of air-cooled steam condenser. Qian et al. [15] explored the effects of orifice on pressure drop in a pilot-control globe

\footnotetext{
Corresponding author: qianjy@zju.edu.cn
} 
valve by mean of experiment and numerical simulation. Hilares et al. [16] employed the response surface methodology to investigate the efficacy of hydrodynamic cavitation which was adopted for pretreatment of sugarcane bagasse. Bokhari et al. [17] applied the orifice plate to cleaner production of rubber seed oil methyl ester, and conducted a parametric optimization by response surface methodology. Zeng et al. [18] applied an orifice plate to a dual-chamber air spring, and analyzed the effects of the shape and number of orifices on the damping characteristics. Karamah et al. [19] used a method of ozonation combined with hydrodynamic cavitation produced by orifice plate to disinfect Escherichia coli bacteria.

The effects of nanofluid on hydraulic cavitation are investigated in this paper. The hydraulic equipment used to induce the cavitation is a 5-hole perforated plate. The alumina nanofluid is employed, of which the nanoparticle volume fraction and the particle diameter are considered as variables. Additionally, the investigation is carried out for different operating conditions.

\section{Analyses and modeling}

In the present research, a pipe channel equipped with a 5hole perforated plate is adopted as the device inducing hydraulic cavitation. The flow channel is symmetric, so a symmetric model is proposed, as Fig. 1(a), and the arrangement of the 5 holes is depicted in Fig. 1(b).

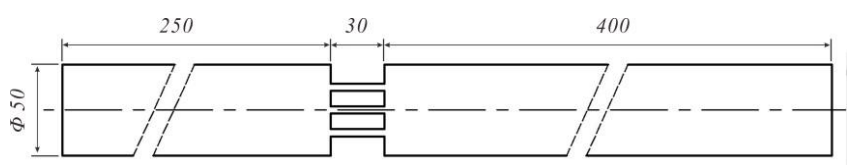

(a) The geometric properties of the model.

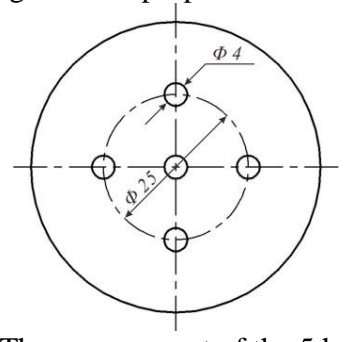

(b) The arrangement of the 5 holes.

Fig. 1. The geometric properties of the model.

The geometric model is discretized by the structured mesh. The elements located at the 5 holes and at the boundary layer have smaller size to promote the simulation accuracy. Mesh independence research has been conducted, and it is found that 1,921,100 elements are sufficient for the accurate numerical simulations.

In this paper, the Realizable k- $\varepsilon$ turbulence model, the mixture model and the Schner-Sauer cavitation model are employed. In terms of the boundary conditions, the inlet is set as a pressure inlet and the outlet is set as a pressure outlet. Additionally, no-slip wall boundary is applied for all walls, and the standard wall function is adopted. In order to validate the numerical method, a numerical simulation has been conducted, and the results are compared with a reported experiment, which was carried out by Kim et al. [20]. The comparison of experiment and numerical simulation is listed in Table 1. The maximum relative error is $9.2 \%$, which indicates the numerical method is reliable.

Table 1. Comparison of experiment and numerical simulation

\begin{tabular}{|c|c|c|c|}
\hline $\begin{array}{c}\text { Differential } \\
\text { pressure } \\
(\mathbf{M P a})\end{array}$ & $\begin{array}{c}\text { Experimental } \\
\text { mass flow } \\
\text { rate (kg/s) }\end{array}$ & $\begin{array}{c}\text { Numerical } \\
\text { simulated } \\
\text { mass flow } \\
\text { rate (kg/s) }\end{array}$ & $\begin{array}{c}\text { The relative } \\
\text { error (\%) }\end{array}$ \\
\hline 0.49 & 2.76 & 2.99 & 8.3 \\
\hline 0.44 & 2.65 & 2.89 & 9.2 \\
\hline 0.40 & 2.53 & 2.73 & 7.9 \\
\hline
\end{tabular}

\section{Results and discussion}

In this investigation, the alumina nanoparticle volume fraction and diameter are considered variables. Besides, the numerical simulations are conducted under different operating conditions, that is the inlet and outlet pressure difference and the temperature are changed. The saturated vapor pressure of alumina nanofluid changes with the nanoparticle volume fraction, the particle diameter and the temperature. Tso et al. [21] have conducted investigations on nanofluid saturated vapor pressure, and a part of the results are listed in Table 2. The effects of alumina nanoparticle volume fraction and diameter at different operating conditions on cavitation are respectively discussed in the following sections.

Table 2. [21] The saturated vapor pressure of alumina nanofluid for different conditions [unit: $\mathrm{Pa}$ ]

\begin{tabular}{|c|c|c|c|c|}
\hline \multirow{2}{*}{$\begin{array}{c}\text { Particle } \\
\text { diameter }\end{array}$} & $\begin{array}{c}\text { Nanoparticle } \\
\text { volume } \\
\text { fraction }\end{array}$ & \multicolumn{3}{|c|}{ temperature } \\
\cline { 2 - 5 } & $0.01 \%$ & $3,176.6$ & $4,294.8$ & $7,493.3$ \\
\hline \multirow{3}{*}{$13 \mathrm{~nm}$} & $0.1 \%$ & $3,135.8$ & $4,222.7$ & $7,458.9$ \\
\cline { 2 - 5 } & $0.5 \%$ & $3,114.1$ & $4,197.7$ & $7,364.2$ \\
\hline \multirow{3}{*}{$20 \mathrm{~nm}$} & $0.01 \%$ & $3,169.0$ & $4,251.8$ & $7,412.8$ \\
\cline { 2 - 5 } & $0.1 \%$ & $3,173.7$ & $4,217.3$ & $7,420.2$ \\
\cline { 2 - 5 } & $0.5 \%$ & $3,105.1$ & $4,171.5$ & $7,333.3$ \\
\hline \multirow{3}{*}{$80 \mathrm{~nm}$} & $0.01 \%$ & $3,138.5$ & $4,220.8$ & $7,395.6$ \\
\cline { 2 - 5 } & $0.1 \%$ & $3,092.9$ & $4,200.1$ & $7,376.1$ \\
\cline { 2 - 5 } & $0.5 \%$ & $3,057.9$ & $4,137.7$ & $7,259.3$ \\
\hline
\end{tabular}

\subsection{The contours of vapour volume fractions}

Figure 2 shows how the vapor induced by the hydraulic cavitation distributes on the symmetry plane. The nanoparticle volume fraction ranges from $0.01 \%$ to $0.5 \%$, the nanoparticle diameter is $20 \mathrm{~nm}$, and the outlet pressure is $0.1 \mathrm{MPa}$. 
In Fig. 2(a), the temperature is $30^{\circ} \mathrm{C}$, and the inlet pressure ranges from 0.4 to $1 \mathrm{MPa}$. It is found that when the inlet pressure is $0.4 \mathrm{MPa}$, the vapor volume fraction varies, while when the inlet pressure is higher, the vapor volume fraction contours are almost the same. It is indicated that with a lower inlet pressure, the nanoparticle volume fraction affects the cavitation of the nanofluid, while the cavitation is dominated by the inlet pressure with a higher inlet pressure.

In Fig. 2(b), the inlet pressure is $0.4 \mathrm{MPa}$, and the temperature ranges from 25 to $40{ }^{\circ} \mathrm{C}$. It is found that the vapor volume fraction changes with the nanoparticle volume fraction. For different temperatures, the laws of the vapor volume fraction changing with the nanoparticle volume fraction vary.

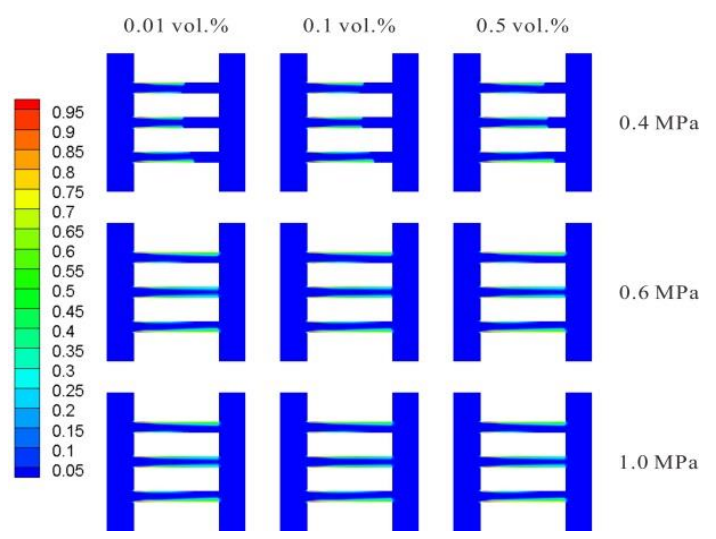

(a) At different inlet pressures

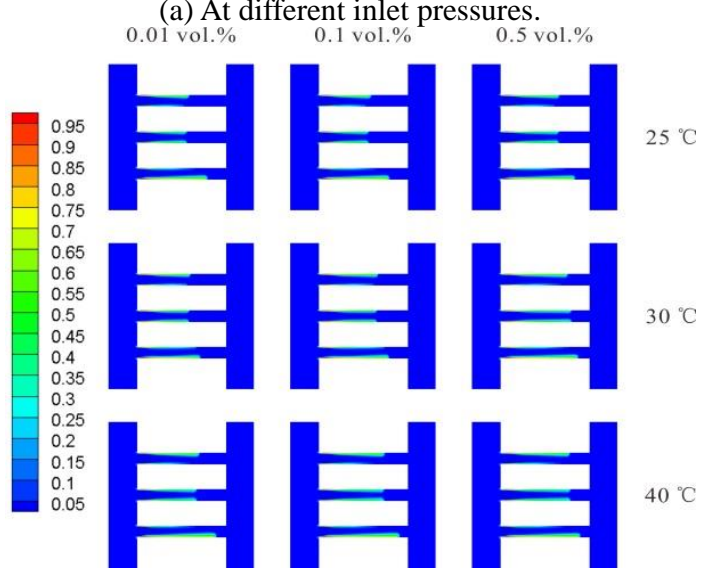

(b) At different inlet temperatures.

Fig. 2. The vapor volume fraction on the symmetric plane for different nanoparticle volume fractions.

Figure 3 shows the vapor distribution on the symmetry plane, of which nanoparticle diameter ranges from 13 to 80 $\mathrm{nm}$, the nanoparticle volume fraction is $0.1 \%$, and the outlet pressure is $0.1 \mathrm{MPa}$.

In Fig. 3(a), the temperature is $30^{\circ} \mathrm{C}$, and the inlet pressure ranges from 0.4 to $1 \mathrm{MPa}$. When the inlet pressure is $0.4 \mathrm{MPa}$, the vapor volume fraction changes with the nanoparticle diameter. When the inlet pressures are 0.6 $\mathrm{MPa}$ and $1.0 \mathrm{MPa}$, the distribution of the vapor are almost the same. It indicates that for a low inlet pressure, the nanoparticle diameter impacts on the cavitation, while for a high inlet pressure, the cavitation is mainly dominated by the inlet pressure.

In Fig. 3(b), the inlet pressure is $0.4 \mathrm{MPa}$, and the temperature ranges from 25 to $40{ }^{\circ} \mathrm{C}$. According to Fig. 3, the vapor volume fraction changes with the nanoparticle diameter. Additionally, the laws of the vapor volume fraction changing with the nanoparticle diameter are different, at different temperatures.

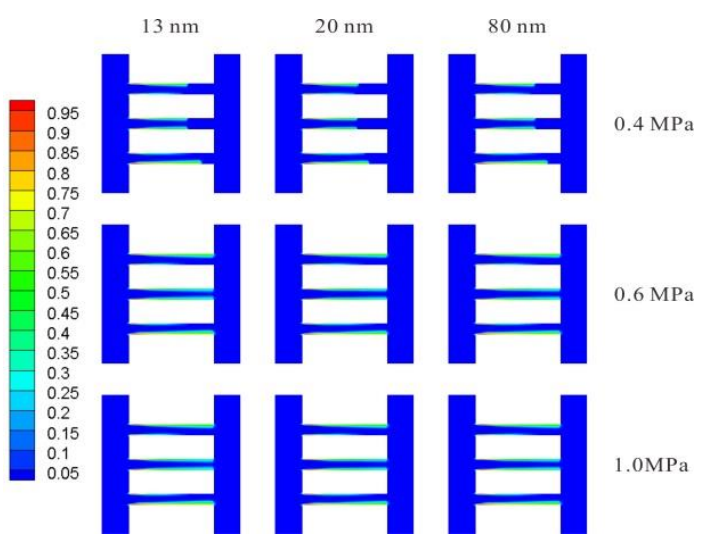

(a) At different inlet pressures.

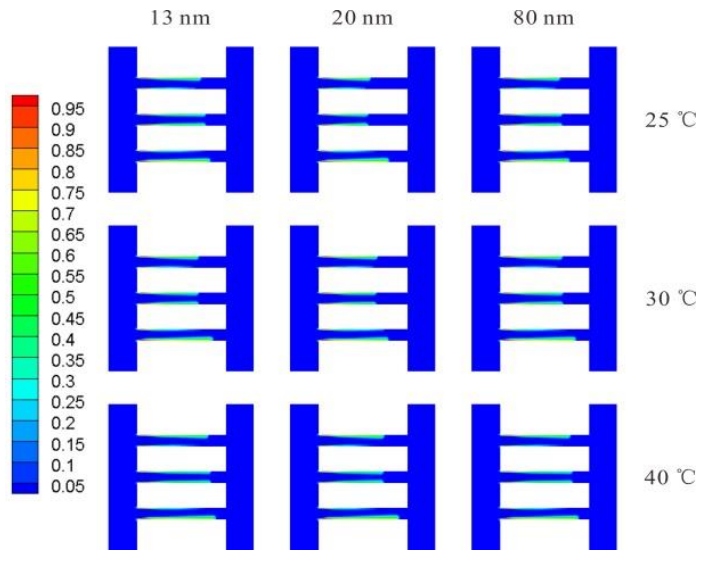

(b) At different temperatures.

Fig. 3. The vapor volume fraction on the symmetric plane for different nanoparticle volume fractions.

\subsection{The cavitation number for different conditions}

The cavitation number is a parameter used to assess the cavitation level. In fact, a smaller cavitation number means a more serious cavitation. The cavitation number on the cross sections of the perforated plate at different conditions are analysed in this section. The inlet of holes is located at $0 \mathrm{~mm}$, and the outlet of holes is located at $30 \mathrm{~mm}$. 
Figure 4 shows the cavitation number with different nanoparticle volume fractions. At a high inlet pressure, the cavitation is mainly dominated by the inlet pressure, so the inlet pressure is set as $0.4 \mathrm{MPa}$ in Fig. 4(a). It can be obtained that, a larger nanoparticle volume fraction leads to a longer section where the cavitation number keeps small. That is to say, for a larger nanoparticle volume fraction, the cavitation will distribute broader. So when the inlet pressure is $0.4 \mathrm{MPa}$, the cavitation level increases with the nanoparticle volume fraction.

In Fig. 4(b), the curves are grouped by temperature. The section where the cavitation number keeps the minimum is longest when the nanoparticle volume fraction is $0.5 \%$, indicating that the cavitation level is the highest. In terms of the other two nanoparticle volume fractions, the section where the cavitation number keeps the minimum is always longer when the nanoparticle volume fraction is $0.1 \%$, but the differences are very small when the temperatures are $25^{\circ} \mathrm{C}$ and $40{ }^{\circ} \mathrm{C}$. That is to say, though a relatively higher nanoparticle volume fraction leads to a more serious cavitation.

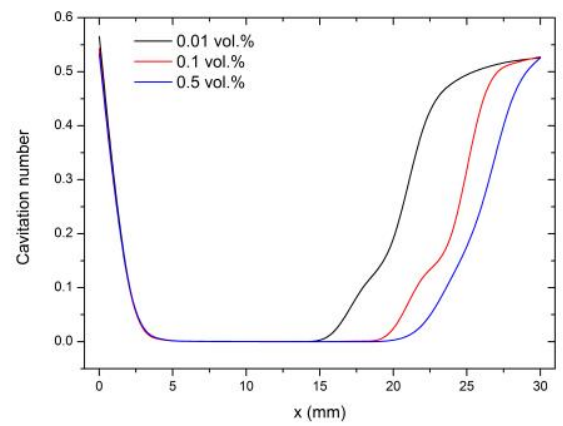

(a) The inlet pressure is $0.4 \mathrm{MPa}$.

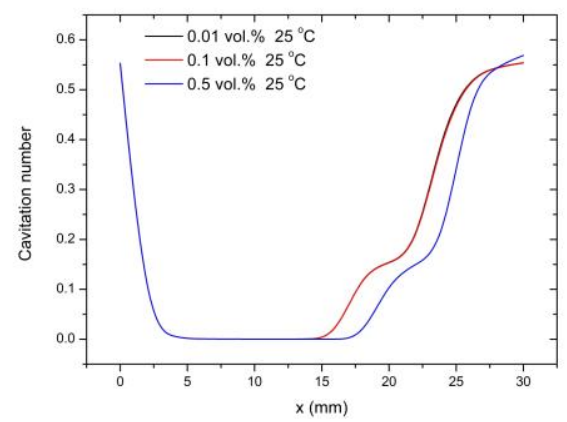

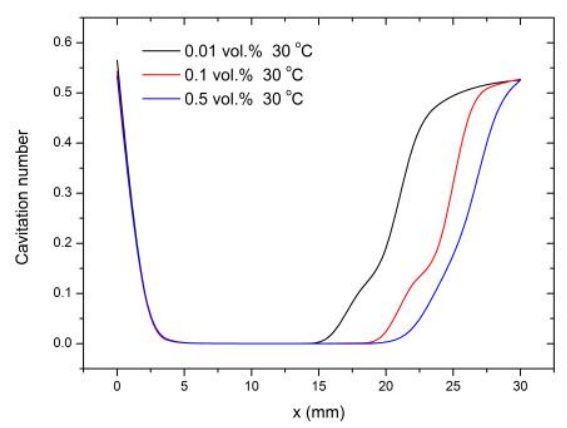

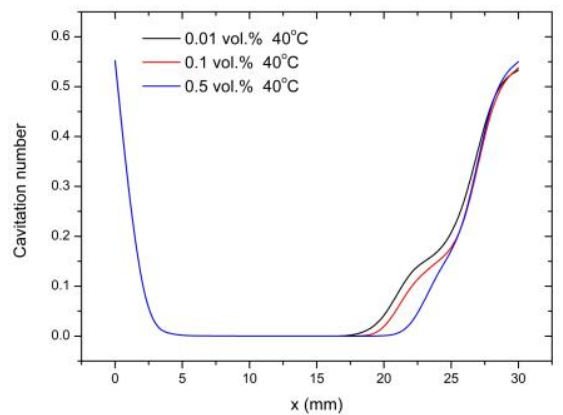

(b) At different temperatures.

Fig. 4. The cavitation number for different nanoparticle volume fractions.

Figure 5 shows the cavitation number with different nanoparticle diameters. Fixing the inlet pressure as 0.4 MPa, Fig. 5(a) depicts the cavitation number. It is found that the three curves are almost overlap, which indicates that when the inlet pressure is $0.4 \mathrm{MPa}$, the nanoparticle diameter affects the cavitation number insignificantly. Fig. 5(b) shows the cavitation number on cross sections of the perforated plate at different temperatures, and the curves are grouped by temperature. When the temperature is 25 ${ }^{\circ} \mathrm{C}$, the difference of cavitation number is the largest, while at other two temperatures, the curves are almost coincident. It can be obtained that at a low temperature, the particle diameter affects the cavitation, while at a high temperature the effects are diminishing.

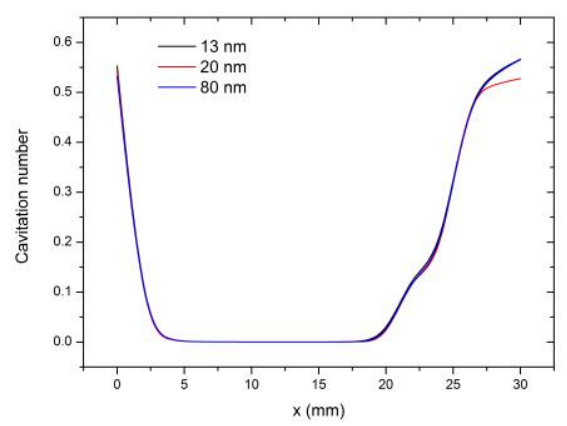

(a) The inlet pressure is $0.4 \mathrm{MPa}$. 

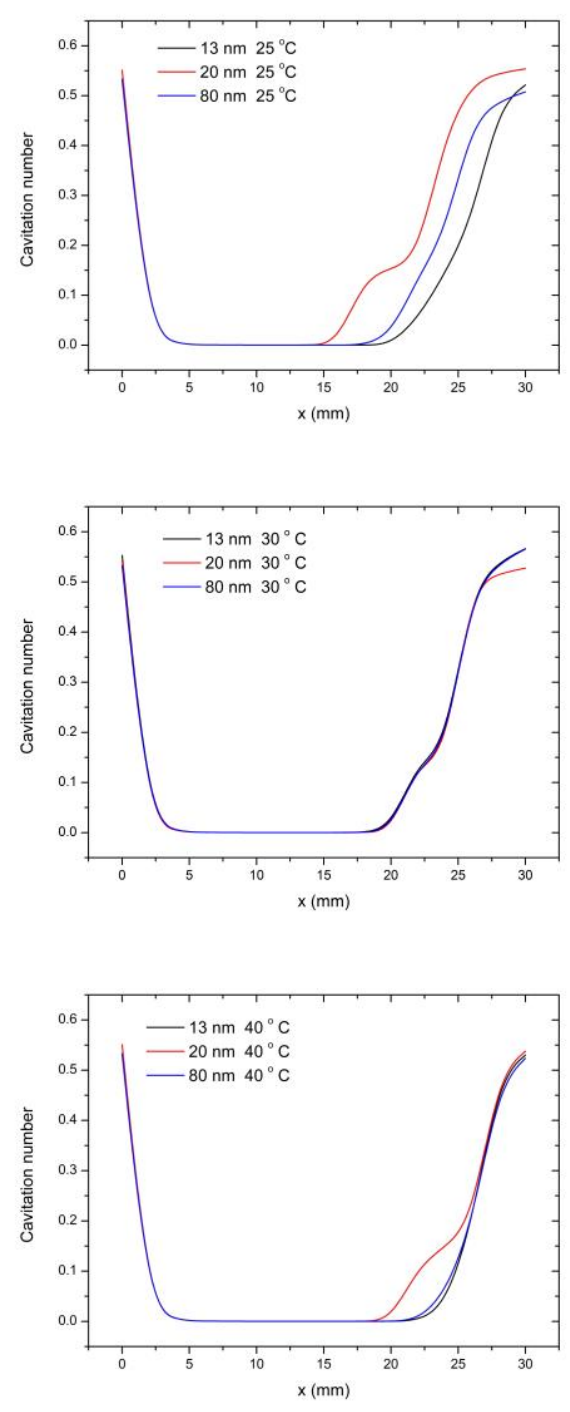

(b) At different temperatures.

Fig. 5. The cavitation number for different nanoparticle diameters.

\section{Conclusions}

The effects of nanoparticles on hydraulic cavitation at different inlet pressures and different temperatures are investigated by mean of numerical simulation. The nanoparticle volume fraction and diameter are considered as variables. The vapor volume fraction and the cavitation number are analyzed, and the following conclusions are obtained:

For a high inlet pressure, the cavitation is mainly dominated by the inlet pressure. On the other hand, for a low inlet pressure, with the increase of the nanoparticle volume fraction, the cavitation increases.

In the temperature range of this investigation, the cavitation increases with the nanoparticle volume fraction, and when at a low temperature, the nanoparticle diameter affects the cavitation significantly.

This work is supported by the Key project of Natural Science Foundation of Zhejiang Province, China through Grant No. LZ17E050002, and the Fundamental Research Funds for the Central Universities through Grant No. 2018QNA4013.

\section{References}

1. B. Ebrahimi, G. He, Y. Tang, M. Franchek, D. Liu, , J. Pickett, F. Springett, D. Franklin, Int. J. Therm. Sci., 114, pp. 229-240, ( 2017)

2. P. Rudolf, D. Kubina, J. Kozák, M. Hudec, F. Pochylý, Meeting of Departments of Fluid Mechanics and Thermodynamics ( 2017)

3. Y. Wang, S. Zhuang, H. Liu, Z. Zhao, M. Dular, J. Wang, J. Mech. Sci. Technol., 31, 7, pp. 3305-3315, (2017)

4. A. A. Araoye, H. M. Badr, W. H. Ahmed, Ann. Nucl. Energy, 104, pp. 75-90, (2017)

5. K. Zhang, Z. Dong, W. Zhao, W. Ju, Y. Li, K. Geng, Z. Qin, L. Wang, J. Hydroelectr. Eng., 36, pp. 56-64, (2017)

6. Z. He, X. Zhang, Y. Chen, C. Ji, J. Jiangsu Univ., Nat. Sci., 38, pp. 416-422, (2017)

7. F. Tao, P. Joseph, X. Zhang, O. Stalnov, M. Siercke, H. Scheel, J. Acoust. Soc. Am., 142, 2, pp. 561-572, (2017)

8. J. Y. Qian, M. Zhang, L. N. Lei, F. Chen, L. Chen, L. Wei, Z. Jin, Energy Convers. Manage., 119, pp. 81-90, (2016)

9. J. Y. Qian, L. Wei, G. R. Zhu, Z. Jin, Energy Convers. Manage., 109, pp. 86-93, (2016)

10. J. Carpenter, S. George, V. K. Saharan, Chem. Eng. Proc. Process Intensif., 116, pp. 97-104, (2017)

11. A. E. Kabeel, M. Abdelgaied, Alexandria Eng. J., 55, 2, pp. 1099-1106, (2016)

12. S. Shaaban, Int. J. Hydrogen Energy, 42, pp. 1462114632, (2017)

13. H. F. Liu, H. Tian, H. Chen, T. Jin, K. Tang, J. Zhejiang Univ. A, 17, 3, pp. 230-239, (2016)

14. X. Zhang, T. Wu, Appl. Therm. Eng., 98, pp. 179-188, (2016)

15. J. Y. Qian, B. Z. Liu, L. N. Lei, H. Zhang, A. L. Lu, J. K. Wang, Z. J. Jin, Int. J. Hydrogen Energy, 41, 41, pp. 18562-18570, (2016)

16. H. R. Terãn, G. F. de Almeida, M. A. Ahmed, Technol., 235, pp. 301-308, (2017)

17. A. Bokhari, F. C. Lai, S. Yusup, J. J. Klemes, M. M. Akbar, M. Kamil, J. Cleaner Prod., 136, pp. 31-41, 
(2016)

18. X. Zeng, L. Zhang, F. Yu, J. Zhou, J. Vibroeng., 19, 4, pp. 2375-2389, (2017)

19. E. F. Karamah, R. Ghaudenson, F. Amalia, S. Bismo, American Inst. of Phys. Conf. Ser., AIP Conference Proceedings 1904, $020075 \quad$ (2017); doi: $10.1063 / 1.5011932$

20. 20. C.Y. Tso, C. Chao,Int. J. Heat Mass Transfer, 84, pp. 931-941, (2015)

21. S. M. Kim, I. C. Bang, Ann. Nucl. Energy, 96, pp. 1218 (2016) 